\title{
Reverse Intra-oral Periapical Radiography For Mandibular Posterior Teeth
}

Nazar Gh Jameel BDS, MDSc (Assist Prof)

\section{Department of Oral and Maxillofacial Surgery}

College of Dentistry, University of Mosul

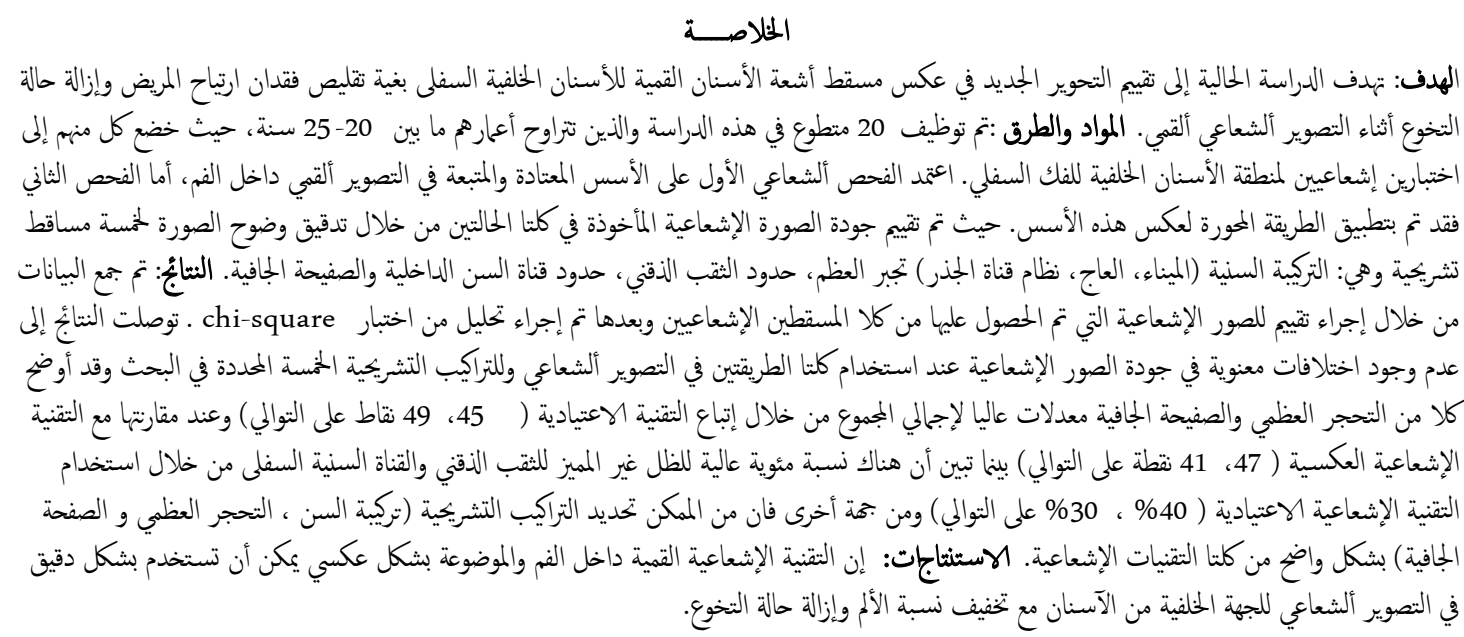

ABSTRACT

Aims: To satisfy the newly reverse modified intra-oral periapical projection, in order to reduce the patient discomfort and eliminate gagging reflex during periapical radiography of the lower posterior teeth. Materials and methods: Twenty voluntaries patients have been used in this research aged between 20-25 years, each patient subjected for two intra-oral periapical radiographic examinations for lower posterior teeth (premolars and molars). The first radiographic examination has been made with ordinary principles of intra-oral periapical radiographic projection, while the second radiograph has been made with reverse modified principles of intraoral periapical radiographic projection. Five independent examiners (two oral radiographer, oral surgeon, oral diagnosis and oral medicine), rated the two radiographic images obtained from both radiographic examination methods. Image quality was assessed by rating the visibility of five anatomical landmarks: tooth structures identification (enamel, dentin and root canal system), bone trabiculation, mental foramen borders, inferior dental canal borders and lamina dura. Results: The data collected from the evaluation of the radiographic images obtained from both radiographic projections were analyzed by paired samples chi-square test, which shown no significant difference $(P>0.05)$ in image quality obtained from both techniques for five selected structures. The bone trabeculae and the lamina dura given higher rating of total score with ordinary technique $(54,49$ points respectively) when compared with reverse radiographic technique $(47,41$ points respectively). The highest percentage of unrecognized shadow of mental foramen and the inferior dental canal with use of ordinary radiographic technique $(40 \%, 30 \%$ respectively), while the other examined anatomic structures (tooth structure, bone trabeculae and lamina dura) can be identified clearly with both radiographic techniques. Higher percentage of gag reflex and pain discomfort was observed with ordinary technique projection (45\%, 40\% respectively) in comparison with reverse technique projection $(0 \%, 5 \%$ respectively). Conclusion: the reverse intra-oral periapical radiographic technique can be used accurately in the radiographic projection of the mandibular posterior teeth; with minimal pain discomforted and with eliminated gagging reflex initiation.

Key Words: periapical radiography, radiographic technique, gagging reflex.

Jameel NG. Reverse intra-oral periapical radiography for mandibular posterior teeth.

Al-Rafidain Dent J. 2010; 10(1):143-150 .

Received: 3/11/2008 Sent to Referees: 6/11/2008

Accepted for Publication: 20/1/2009

\section{INTRODUCTION}

Periapical radiography describes intraoral techniques designed to show individual teeth and the tissues around the 
apices. Each film usually shows two to four teeth and provides detailed information about the teeth and the surrounding alveolar bone ${ }^{(1)}$. Intraoral radiography could be performed by either the bisecting-angle or the paralleling technique ${ }^{(2)}$. Periapical radiography is not always as straight forward in practice as it appears in theory. However, knowledge of the theoretical requirements of imaging enables the clinician to modify the available techniques to suit individual needs of patients (1).

The high muscle attachments in the floor of the mouth on the lingual surface of the mandible sometime make it almost impossible to insert a film deep enough and sufficiently far toward the midline to record the entire examined tooth and the surrounding tissues, including the inferior dental canal. ${ }^{(1,3)}$.

The gag reflex is common to all people but is more active in some than in another. This makes the placement of the film packet in the desired position particularly difficult, especially in the upper and lower molar regions ${ }^{(3,4)}$.

Aims of the study includes the followings;

1. To evaluate the newly reverse modified intra-oral periapical projection for lower posterior teeth regarding the image quality.

2. Reduce the patient discomfort and the gagging reflex during periapical radiography of the lower premolar teeth.

\section{MATERIALS AND METHODS}

Twenty volunteers were enrolled in this research with ages between 20-25 years (12 males and 8 females), each patient was subjected to two intra-oral periapical radiographic examinations for lower posterior teeth (premolars and molars). The first radiographic examination performed was based on ordinary principles of intra-oral periapical radiographic projection (Figure 1).

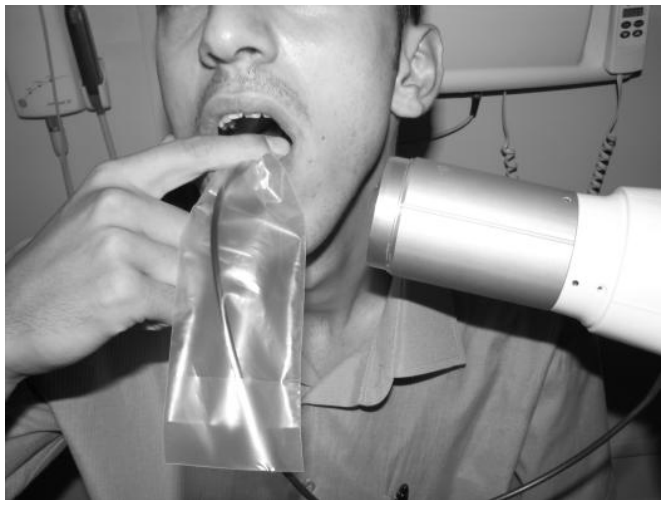

Figure (1): Represent the $\mathrm{x}$-ray beam, object and image receptor alignment with ordinary intra-oral periapical radiographic technique.

While the second radiograph was performed with reverse modified prin- ciples of intra-oral periapical radiographic projection. (Figure 2).

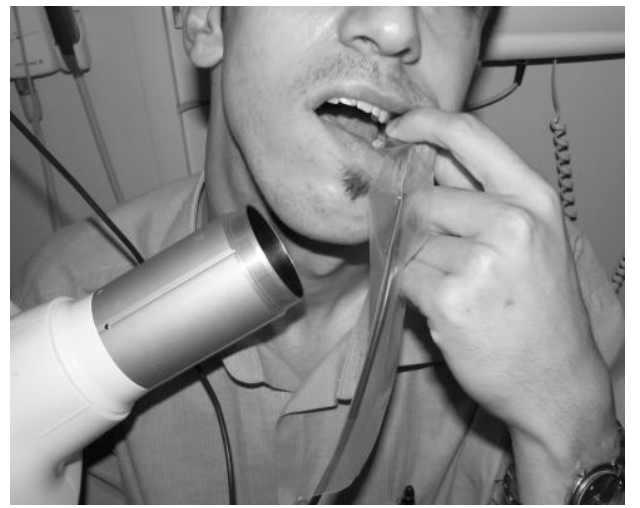

Figure (2): Represent the X-ray beam, object and image receptor alignment with reverse intra-oral periapical radiographic technique. 
The principles of bisecting angle technique were applied with both projections. Dimax-3 digital system PLANMECA, Helsinki, Finland was operated at $70 \mathrm{kVp}, 8 \mathrm{~mA}$ and 0.025 sec. exposure time, with size 2 CCD $\mathrm{x}$-ray digital sensor was used. Altogether, the digital images files were displayed on 17 inch monitor, brightness and contrast were fixed and no enhancement was made before the digital images files were saved.

Bisected Angle Technique Principles: The theoretical basis of the bisected angle technique can be summarized as follows ${ }^{(1,}$ 3,5):

- The angle formed between the long axis of the tooth and the long axis of the image receptor is assessed and mentally bisected.

- The central ray is directed perpendicular to the bisector of the angle formed by the long axis of the tooth and the plane of the image receptor.

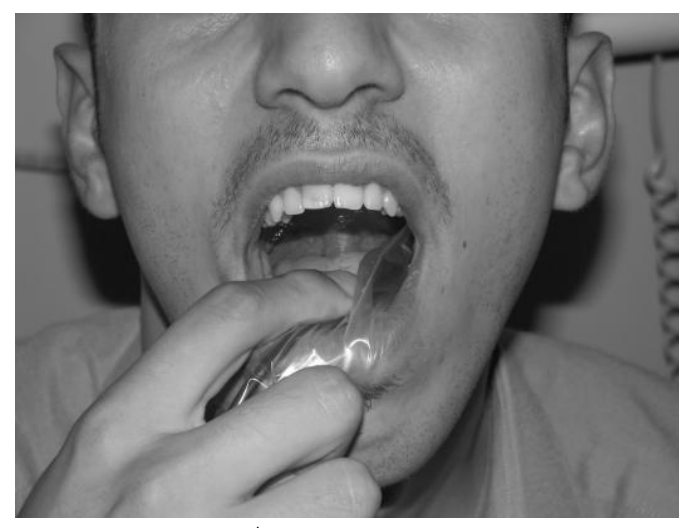

A
- Correct horizontal angulation exists when the central ray is perpendicular to the facial surfaces of the teeth and parallel to the mesial and distal surfaces.

- The patient head should be positioned so that the occlusal surfaces of the mandibular teeth will be horizontal when the mouth is opened and the median plane is vertical to the horizontal plane.

Reverse Technique Principles: the principles of bisecting angle technique were applied with the direction of the primary $\mathrm{x}$-ray beam in both vertical and horizontal angulations, but with following modifications;

- The image receptor position was reversed to be placed in the buccal vestibule instead of lingually positioned as in ordinary intra-oral periapical radiographic projection (Figure 3; A \& B).

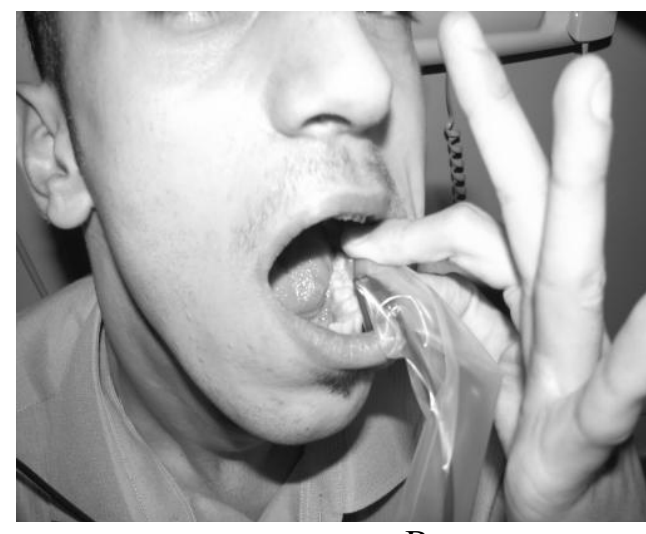

B

Figure (3): Represent the image receptor position with the both radiographic techniques. A; Ordinary intra-oral periapical radiographic technique.

B; Reverse intra-oral periapical radiographic technique.

- The primary $\mathrm{x}$-ray beam is directed to the bisecting line from the lingual side, with the beam of x-ray machine coming under the lower border of the mandible from the opposed side not to be examined toward the region to be examined.

- Correct horizontal angulation exists when the central ray passes parallel to the mesial and distal surfaces of the examined teeth as in the ordinary viewing.
- The patients head should be tilted laterally towards the examination side to facilitate the positioning of the head of x-ray machine to make the primary $x$-ray beam at right angle of the bisecting line (Figure 2).

Five independent examiners (two oral radiographers, oral surgeon, oral diagnosis and oral medicine), rated the two radiographic images (Figure 4) obtained from both radiographic ex- 
amination methods on a three point scale: $(0=$ unidentified structure, $1=$ poor, $2=$ fair, $3=$ good). Image quality was assessed by rating the visibility of five anatomical landmarks:

- Tooth structure identification (enamel, dentin and root canal system).

- Bone trabiculation.

- Mental foramen borders.

- Inferior dental canal borders.

- Lamina dura.

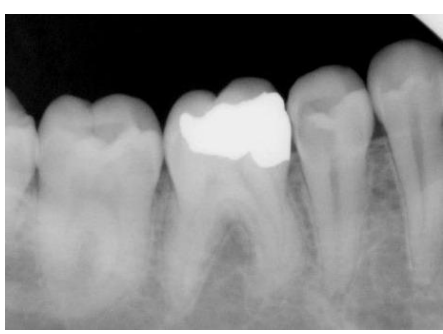

A

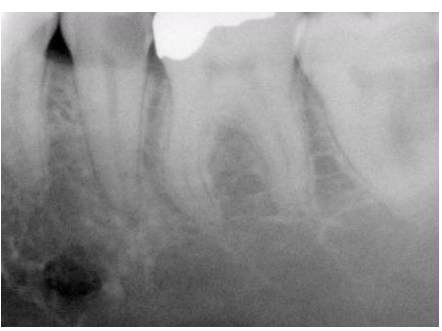

D

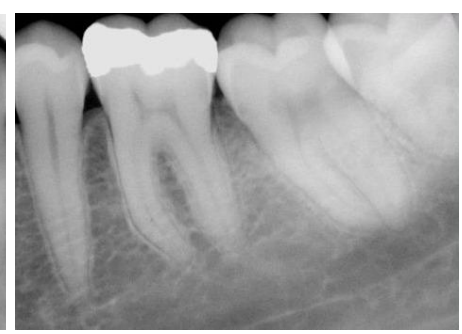

B

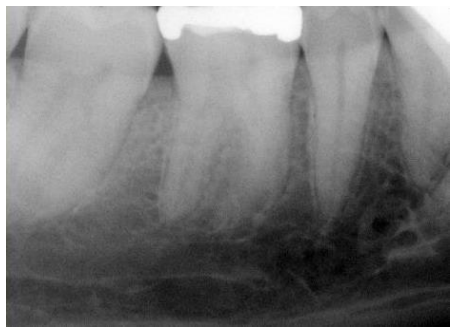

E

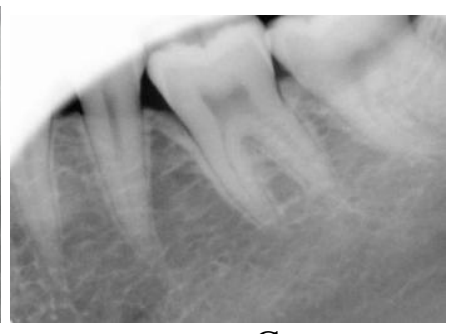

C

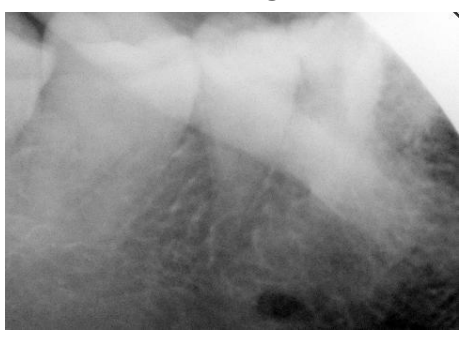

$\mathrm{F}$

Figure (4): Represent the radiographic images obtained by two radiographic techniques. (A,B,C; obtained by the ordinary intra-oral periapical radiographic technique) (D,E,F: obtained by the reverse intra-oral periapical radiographic technique).

With the use of formatted case sheet for each image, (Figure 5), the given landmark was rated as good (image of excellent diagnostic quality), fair (image of diagnostic quality but should be improved), or poor (image not of di- agnostic quality) and scale (0) was given to the structure can not be shown by the radiograph Each image was then given an overall evaluation rating of good, fair, or poor.

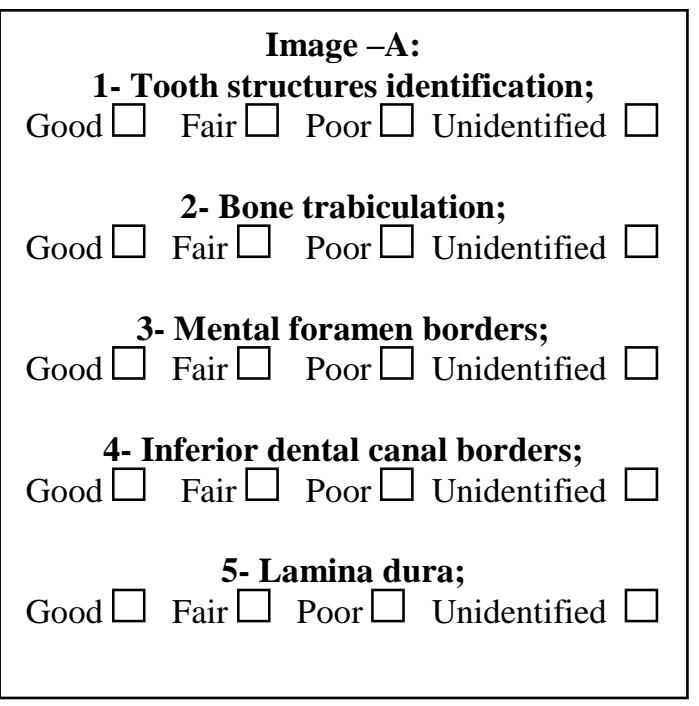

\begin{tabular}{c} 
Image -B: \\
1- Tooth structures identification; \\
Good $\square \quad$ Fair $\square \quad$ Poor $\square$ Unidentified $\square$ \\
2- Bone trabiculation; \\
Good $\square \quad$ Fair $\square \quad$ Poor $\square$ Unidentified $\square$ \\
Good $\square \quad$ Fair $\square \quad$ Poor $\square$ Unidentified $\square$ \\
4- Inferior dental canal borders; \\
Good $\square \quad$ Fair $\square \quad$ Poor $\square$ Unidentified $\square$ \\
5- Lamina dura; \\
Good $\square \quad$ Fair $\square$ Poor $\square$ Unidentified $\square$ \\
\hline
\end{tabular}

Figure (5): formatted case sheet. 
Each patient was asked about any discomfort (pain and gag reflex) and his /her opinion concerning the simplicity in the image receptor positioning to evaluate and compare both projection modalities.

\section{RESULTS}

The data collected from the evaluation of the radiographic images obtained from both radiographic projections by the five examiners, were analyzed by paired samples chi-square test with Excel-Microsoft stastical software program, which showed no significant difference $(P>0.05)$ in image quality obtained from both techniques for five selected structures (Table 1).

Table (1): Evaluation of the radiographic images obtained from both radiographic projections was analyzed by t-test.

\begin{tabular}{c||c|c|c|c|c}
\hline Structures & $\begin{array}{c}\text { Viewing } \\
\text { Technique }\end{array}$ & $\begin{array}{c}\text { Total } \\
\text { grad }\end{array}$ & SD. & Chi^2 value $P>0.05$ \\
\hline Tooth struc- & $\mathrm{O}$ & 52 & 0.502625 & 3.162 & 0.99998 \\
tures & $\mathrm{R}$ & 50 & 0.512989 & & \\
Bone trabe- & $\mathrm{O}$ & 54 & 0.571241 & 2.8619 & 0.99999 \\
culae & $\mathrm{R}$ & 47 & 0.74516 & & \\
Mental fo- & $\mathrm{O}$ & 17 & 0.812728 & 8.4768 & 0.97066 \\
ramen & $\mathrm{R}$ & 48 & 0.8207826 & & \\
IDC. & $\mathrm{O}$ & 22 & 0.91191 & 11.335 & 0.91206 \\
& $\mathrm{R}$ & 51 & 0.5104177 & & \\
Lamina dura & $\mathrm{O}$ & 49 & 0.510418 & 2.3743 & 2.3743 \\
\hline
\end{tabular}

IDC: Inferior dental canal., O:Ordinary radiographic technique, R: Reverse radiographic technique.

The image quality, as represented by each of the five anatomical landmarks, and the overall rating for each technique were expressed as the mean scores of the five examiners as shown in the (Table 2), where the bone trabe- culae and the lamina dura revealed higher rating of total score with ordinary technique $(54,49$ points respectively) when compared with the reverse radiographic technique $(47,41$ points respectively).

Table (2): The image quality represented by the overall rating for each technique with the five anatomical landmarks.

\begin{tabular}{ccccccccc}
\hline Structure & \multicolumn{4}{c}{ Ordinary radiographic tech- } & \multicolumn{4}{c}{ Reverse radiographic technique } \\
& Good & Fair & Poor & Total & Good & Fair & Poor & Total \\
\hline $\begin{array}{c}\text { Tooth } \\
\text { structures }\end{array}$ & 36 & 16 & 0 & 52 & 30 & 20 & 0 & 50 \\
$\begin{array}{c}\text { Bone tra- } \\
\text { beculae }\end{array}$ & 45 & 8 & 1 & 54 & 30 & 14 & 3 & 47 \\
$\begin{array}{c}\text { Mental } \\
\text { foramen }\end{array}$ & 0 & 10 & 7 & 17 & 33 & 14 & 1 & 48 \\
$\begin{array}{c}\text { IDC. } \\
\text { Lamina } \\
\text { dura }\end{array}$ & 3 & 12 & 7 & 22 & 33 & 18 & 0 & 51 \\
\hline
\end{tabular}

IDC: Inferior dental canal. 
The total number and percentage of unidentified anatomical structures marked in the radiographic image obtained from each projection modalities are shown in the (Table 3), where the highest percentage of unrecognized shadow of mental foramen and the inferior dental canal was with the use of ordinary radiographic technique (40\%, 30\% respectively), while the other examined anatomic structures (tooth structure, bone trabeculae and lamina dura) can be identified clearly with both radiographic techniques.

Table (3): The number and percentage of unidentified structures in the radiographic image obtained from both radiographic projection techniques

\begin{tabular}{lcccc}
\hline \multirow{2}{*}{$\begin{array}{l}\text { Anatomical Struc- } \\
\text { ture }\end{array}$} & \multicolumn{3}{c}{$\begin{array}{c}\text { Ordinary radiographic tech- } \\
\text { nique }\end{array}$} & $\begin{array}{c}\text { Reverse radiographic tech- } \\
\text { nique }\end{array}$ \\
\cline { 2 - 5 } & No. & $\%$ & No. & $\%$ \\
Tooth structures & 0 & 0 & 0 & 0 \\
Bone trabeculae & 0 & 0 & 0 & 0 \\
Mental foramen & 8 & 40 & 1 & 5 \\
IDC. & 6 & 30 & 0 & 0 \\
Lamina dura & 0 & 0 & 0 & 0 \\
\hline
\end{tabular}

IDC: Inferior dental canal.

Table 4; shown no patient having a gag reflex $(0 \%)$ and only single case shows pain discomfort $(5 \%)$ when the reverse technique was used. While $45 \%$ of ex- amined cases having gag reflex and $40 \%$ suffering from pain discomfort with ordinary technique projection.

Table(4): The number and percentage of gag reflex and pain discomfort findings obtained from the use of both radiographic projection techniques

\begin{tabular}{cccccc}
\hline & $\begin{array}{c}\text { Total } \\
\text { samples } \\
\text { No. }\end{array}$ & $\begin{array}{c}\text { Ordinary radiographic } \\
\text { technique }\end{array}$ & $\begin{array}{c}\text { Reverse radiographic } \\
\text { technique }\end{array}$ \\
& 20 & No. & $\%$ & No. & $\%$ \\
Gag reflex & 9 & 45 & 0 & 0 \\
Pain discomfort & 20 & 8 & 40 & 1 & 5 \\
\hline
\end{tabular}

\section{DISCUSSION}

Periapical radiography is designed to give diagnostic images of the apical portions of teeth and their adjacent tissues. The tissues to be radiographed and the $\mathrm{x}$ ray beam must be in proper relationship to produce an accurate radiographic image. This is particularly important when using the bisecting angle technique ${ }^{(4)}$.

Morphological variations from mouth to mouth and even within the same oral cavity pose a variety of geometric problems which must be continuously modified to accommodate the immediate circumstances ${ }^{(3)}$.

The selected age group of the patients (20-25 years) facilitates the exclusion of the effect of exposure factors on the final image quality, were they fixed at $70 \mathrm{kVp}$, $8 \mathrm{~mA}$ and 0.025 exposure time.

Evaluation of the data collected by the five examiners showed that there was no significant difference $(P>0.05)$ in the image quality of the selected anatomic structures in both projection modalities, (Table 1). This means that all modifica- 
tions had been done on the ordinary intraoral radiographic projection technique for lower posterior teeth with no adverse effect on the image quality and the diagnostic ability of the examiner.

Image receptor positioning: the image receptor (CCD sensor) was supported in its place simply by the patient index finger with pressure on the upper edge of the sensor in an apical direction. The presence of buccal muscles prevent its bending, slipping and kept it fixed in its place easily. This simplified the reverse radiographic technique for both the patient and operator ${ }^{(6)}$.

Apical area coverage: the support of the image receptor by the patient index finger facilitates partial opening of the patient mouth. This will lead to facial muscle relaxation and facilitate enough apical extension of image receptor with minimal patient discomfort ${ }^{(1)}$.

Vertical angulation of the beam: the buccal positioning of the image receptor with the presence of muscle attachments make the angle formed between the long axis of the object and long axis of the image receptor will be increased as a result of increasing the buccal inclination of the bisecting imaginary line, the vertical angles are often quoted but inevitably they are only approximate $^{(5)}$. Therefore the oblique direction of the primary $\mathrm{x}$-ray beam compensated by the buccal inclination of the imaginary bisecting line facilitates the direction of the primary beam in an approximated right angle to the bisecting line ${ }^{(7)}$.

Mental foramen: It is clinically significant to accurately identify the location of the mandibular foramen, canal wall, mental foramen, and so on, all of which transmit inferior alveolar nerves ${ }^{(8)}$. The overall view of rating (Table 2) showed that the mental foramen shadow is highly identified with reverse technique in comparison with ordinary technique. This is related to the location of the mental foramen which is closer to the image receptor in the reverse technique that makes its shadow more sharply. The parts of the object farther away from the film are projected in an incorrect relationship to those parts closer to the film ${ }^{(9)}$, the shadow of mental foramen was unrecognized in $40 \%$ of radiographic images produced by the ordinary radiographic projection. This is related to the opening of the mental canal which is directed superiorly and posteriorly and as a result, the usual view of the premolars is not projected through the long axis of the canal opening (3).

Inferior dental canal: the inferior dental canal was identified sharply in all radiographic images produced by the reverse technique (Tables 2, 3), where the shadow of inferior dental canal cannot be shown in about $25 \%$ of periapical radiographs taken with ordinary technique. This is related to the oblique direction of the $\mathrm{x}$-ray beam coming lingually to expose the inferior dental canal ${ }^{(3)}$.

Gag reflex and pain: no patient experienced gag reflex when the reverse technique was used $(0 \%)$, while the gag reflex is highly initiated in the intra-oral radiographic examination of mandibular posterior teeth with ordinary technique projection $(45 \%)$. In the reverse technique the image receptor was placed away from the zone that initiate gag reflex and supported with index finger of the patient press over its the upper boarder with minimal mouth opening ${ }^{(10)}$.

Only one case represented pain discomfort with the reverse technique $(5 \%)$ when compared with ordinary technique projection is used (40\%). This may be due to swelling extending to the buccal vestibule that makes the positioning of the image receptor so difficult and painful to the patient. Therefore this technique is difficult to be used with those patients having buccal or facial swelling ${ }^{(11)}$.

Image orientation: as the $\mathrm{x}$-ray beam is directed reversely from the lingual side of the examined region. In addition, the exposure side of the image receptor is reversed to oppose the source of radiation. Therefore, the right side of the image represented the left side of the patient if the image is viewed in the buccal mounting or it represents the same side of the patient if it's viewed in the lingual mount- 
ing. However, the film is oriented with the convex side of the dot towards the viewer (3)

Difficulty of technique: high training and practical experience is required by the operator to perform adequate and correct alignment of the x-ray beam to be at a right angle to the bisecting line.

\section{CONCLUSIONS}

It is concluded that the reverse intra-oral periapical radiographic technique can be used accurately in the radiographic projection of the mandibular posterior teeth;

1. It can be used as an alternative to the ordinary radiographic projection in the examination of mental foramen and inferior dental canal.

2. With minimal pain discomfort and with eliminated gagging reflex initiation.

3. The reverse orientation of the final radiographic image should be noted in the viewing of the radiograph.

4. Special training and experience of the operator is required in the alignment of the $\mathrm{x}$-ray beam with the bisecting line.

This technique is difficult to be used with patients having facial or buccal swelling.

\section{REFERENCES}

1. Eric Whaites . Essentials of dental radiography and radiology. $3^{\text {rd }}$ ed. Churchill Livingstone. Edinburgh. 2002; 89-110.

2. Manson Hing L.H. What's' the angle, study of the angle bisected in intraoral radiography. Oral Surg. 1980; 99. (I): 86 -
89.

3. White SC, Pharoah MJ. Oral radiology principles and interpretation. 4th ed. CV Mosby, St. Louis. 2000; 133-169.

4. Wuehrmann AH, Manson-Hing LR. Dental radiology, $5^{\text {th }}$.ed, St Louis, CV Mosby. 1981; Pp 98- 218.

5. Rita A. Mason. A Guide to Dental Radiography. $2^{\text {nd }}$ ed. Oxford, Wright. 1982; 33-41

6. Thomas F. Razmus \& Gail F. Williamson: Current Oral and Maxillofacial Imaging. Philadelphia, W. B. Sanders Company.1996; 75- 168.

7. Chinami Igarashi, Kaoru Kobayashi, Akira Yamamoto, Yasuhiko Morita, Mamoru Tanaka. Double mental foramina of the mandible on computed tomography images: a case report. Oral Radiol .2004; 20:68-71.

8. Allan G. Farman, Taeko T. Farman. A status report on digital imaging for dentistry. Oral Radiol. 2004; 20: 9-14.

9. Updegrave W.J. Simplifying and improving intraoral dental roentgenography. Oral Surg. 1959; 12 (6): 704.

10. William W. Wainwright, George M Hollenback. General Rules in Periapical Radiography. Dental Radiology. $5^{\text {th }}$ ed. New York, McGRAW-HILL Book Company.1965; Pp 173.

11. Gordon R. Seward, Malcolm Harris, David A. McGrwan: Pyogenic Infection of the soft tissues. An Outline of Oral Surgery (Part $-\mathrm{I})$. Oxford, Wright. 1998; Pp 121-124. 